\title{
Knowledge Modelling of E-maintenance in Industrial Robotics
}

\author{
Adrian Chioreanu, ${ }^{1, a}$, Stelian Brad ${ }^{2, b}$ and Emilia Brad ${ }^{3, c}$ \\ ${ }^{1,2,3}$ Research Lab of Competitive Engineering in Design and Development \\ Technical University of Cluj-Napoca, Cluj-Napoca, 103-105 Muncii Av., 400641, Romania \\ aadrian.chioreanu@com.utcluj.ro (corresponding author), \\ bstelian.brad@staff.utcluj.ro, \\ `emilia.brad@muri.utcluj.ro
}

Keywords: E-maintenance, Knowledge Modeling, Ontology, Industrial Robotics

\begin{abstract}
Nowadays providers of maintenance and support related to industrial robotics are facing major challenges. Equipment producers around the world are urged to make significant efforts in order to provide high value added services in addition to their traditional product development and manufacturing business. A focal problem with maintenance as well as support of industrial robotics is the need to manage the ever-increasing information flow and system complexity of production cells that incorporate equipment from different producers. In this context, a novel ontology-based representation model is developed for the sharing and use of maintenance knowledge in the robotic field.
\end{abstract}

\section{Introduction}

Due to the emergence of new technologies, the shift in customer expectations and environmental as well as resources provision paradigms, the manufacturing industry was faced with an unprecedented degree of change in the last three decades, involving drastic changes in management approaches, product and process technologies. Production companies nowadays are under constant pressure from consumers, competitors, retail sector, each trying to shape not only the products themselves but also the way in which they are produced, consumed and disposed.

Today business environment is characterized by fierce competition not only on price levels but also on the raw materials supply side, doubled by volatility in consumer's demands. Those fast changes call for production companies to make effective improvements in the way goods are designed. To survive in today's highly competitive business environment organizations must improve at a faster pace than competitors do, if they aim to remain competitive, yet alone to be leaders in their field of activity.

To meet the challenges posed under the present competitive environment, manufacturing companies must think beyond producing a quality product, they must incorporate value for the customers into the product. This value may be achieved one way or another, but a new trend is towards increasing value for money by supporting the customer during the entire life of the product through the creation of clear maintenance policies.

Cost effective manufacturing has become a necessity, it's not a differentiating asset. Customers factor in also the cost of using, maintaining, upgrading and disposing the equipment when deciding to purchase.

Until recent times, the maintenance aspects related to products was of second importance to management, as much of their attention was addressed on improving manufacturing productivity by planning, measuring, reporting and analyzing the manufacturing process.

\section{Background information}

Maintenance function. Managers try to associate to each of their actions a return on investment indicator. Even if industrial equipment producers taken into consideration the development of maintenance and support documentation, as early as on the design phase [1], the general perception 
in the ranks of producers as well as users is that maintenance has a poorer rate of return than any other major budget chapter.

A survey on manufacturers found, that in financial terms, maintenance is responsible for around 20 to 40 per cent of the value added to a product as it moves through a production facility. Full-time maintenance personnel averaged 15 per cent of overall staffing in manufacturing organizations [2]. By acknowledging maintenance importance and placing it on the right priority, companies were able to cut maintenance overheads by at least one-third [2], and at the same time improve the level of productivity and the perception of the market on the company products.

Computer Maintenance Management Information Systems. With the increase of systems complexity, companies are faced with complex maintenance procedures as well, often involving hundreds of suppliers, service providers, and documented procedures. This is increasing the pressure on companies that have to deal with the management of both tangible assets as well as intangible assets (knowledge) related to maintenance. To cope with this challenge companies had begun to use ever more complex Computerized Maintenance Management Information System (CMMIS). The number of CMMIS that are available on the market and used in almost every industrial field has grown very steeply during the last period [9]. Scientific papers, dated as early on as 1995 [10] foreseen the development of complex maintenance systems. Efforts to create emaintenance systems started to materialized into CMMIS from 2000 [11].

Knowledge management. Knowledge describing a certain domain may be formalized with the help of an ontology [3]. Ontologies are used to structure knowledge as a set of concepts and relations between concepts. Although XML are sufficient for exchanging data based on an agreed schema, their lack of semantics prevents machines from reliably performing this task when new XML vocabularies and rules are taken into consideration. The use of ontologies in the field of robotics has been address by multiple projects [4] in the past. An ontology may be defined and described using the OWL (Web Ontology Language) standard. For the definition E-maintenance ontology, that is subject of this paper, three elements of OWL were extensively used, namely: namespace, class and property. One must understand that there is a clear distinction between ontologies designed to be used directly by robots during their operation and ontologies suitable to model the robotic domain, even if they might have some overlapping elements.

\section{Aim of research}

This paper aims at reporting the goals we reached towards facilitating the transfer of knowledge related to the maintenance of industrial robotics among producers, integrators, academics/researchers and users (e.g. SMEs) by means of an maintenance ontology. The research here presented aimed at creating a prototype ontology based CMMIS (e-Maintenance system) able to collect and use knowledge present in various stakeholders' portfolios. Using ontologies as opposed to databases and XMLs, might increase the flexibility of the CMMIS as new knowledge may be easily added to the repository.

The first part of the paper is dedicated to the ontology used to structure the maintenance process for industrial robotics so that the development of an e-maintenance system capable of being queried for appropriate actions is rendered possible. The second part describes a case study showcasing how the formalized maintenance knowledge may be used.

Our main goal was to create an ontology that facilitates the sharing of maintenance knowledge e.g.: maintenance procedures, required maintenance resources, red flag trigger parameters, etc. Further we tried to showcase the extent to which this concept may be used in the field of industrial robotics maintenance.

One concern in the design phase was to create a solution that will enable producers to incorporate more value into their products, by creating a flexible CMMIS. The clear aim was to design a solution that may help SMEs to easily integrate into their production new robotic technologies by diminishing the operational and maintenance costs and by providing a collaborative platform for gathering and generating new knowledge related to maintenance. 


\section{Proposed E-maintenance ontology}

The main factors that influence a maintenance policy and its application are not always entirely foreseen by the equipment producers and more than this are not under their direct control. Maintenance policy aspects such as timing and allocation of resources (material as well as human resources) is to be shaped by technological and knowledge limitation and the needs of the customer (e.g. tolerance to failures and shutdowns), as well as by the operational environment (humidity, particle presence, vibrations, etc.) and customer organization structure (externalized maintenance vs. employed maintenance engineers). Thus the maintenance policy generally released by the manufacturer should be amended in order to suit all those factors that may differ from one user to another [5]. An information system able to capture maintenance knowledge from both producers and integrators/service entities is supposed to ease such an approach.

As noted in previous researches [6] there are several stakeholders involved in the industrial robotics field. We determined each stakeholder (industrial robots producers, integrators, researchers, academics) interest and involvement in the maintenance process, by dividing the maintenance process into distinct phases [7]: maintenance management, maintenance support planning, maintenance preparation, maintenance execution, maintenance assessment and maintenance improvement. The reason behind this separation of concern, Fig. 1, was to determine how the ontology design process should be approached. This simple reasoning proved that the ontology structure should be designed starting from knowledge present in producers and R\&D (research and development entities) portfolios, that should later be amended through the eyes of integrators. Academics in this case have the role to follow through the whole process in order to structure the relevant knowledge. Once the ontology schema is created, the ontology may be populated with individuals, which are more likely to be members of multiple classes. The population of the ontology is a process that includes all stakeholders (users as well) with different involvement levels and at different stages.

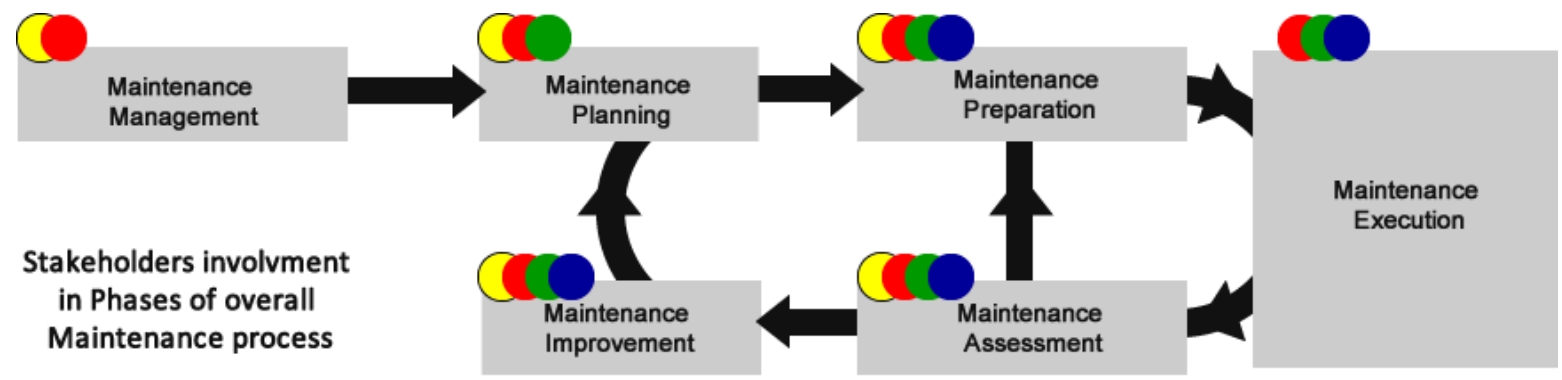

Users R\&D, Academics Integrators
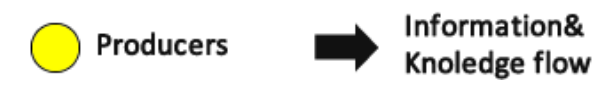

Fig. 1. Involvement of stakeholders in the phases that define the overall maintenance process

We adopted the open world approach (OWA) for designing the E-maintenance ontology in order to be able to face unexpected factors that may affect the maintenance policy and its applications, factors such as: loose requirements addressed by users, changes in legislation, environment changes, and new economic paradigms [8]. OWA will consent for the ontology to support an ongoing evolution not only in terms of individuals (instances) but also in terms of new rules and links between classes.

In order to effectively define the knowledge hierarchies and the relationships between them, an appropriate representation scheme (ontology) is adopted, Fig. 2. The proposed E-maintenance ontology handles knowledge structured on different ontology packages, namely:

- Product;

- Maintenance resources; 
- Maintenance knowledge;

- Problem knowledge;

- Intervention knowledge.

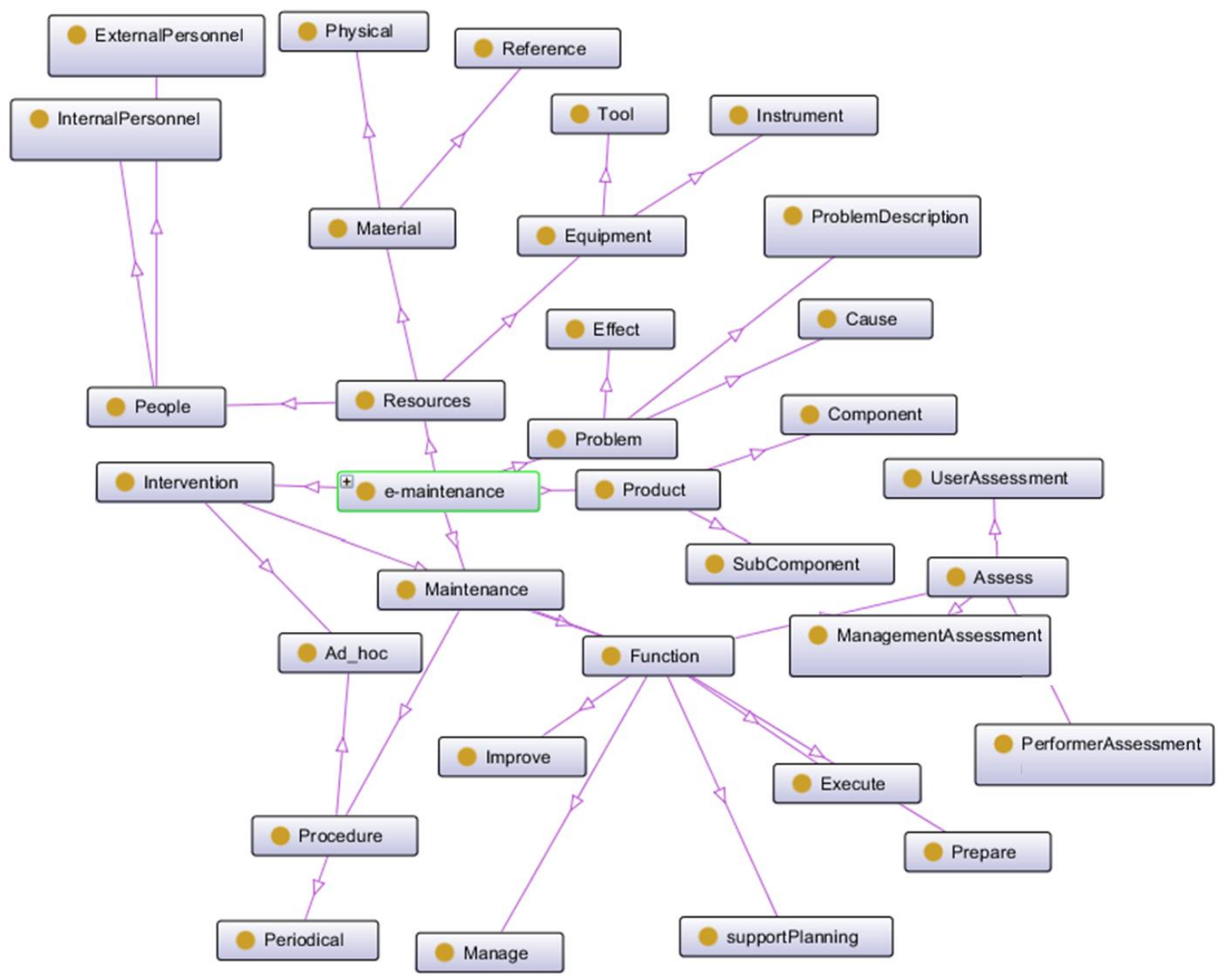

Fig. 2. Proposed E-maintenance ontology nodes as seen in the Protégé graph representation.

Product refers to industrial robotic capabilities that are to be affected by maintenance policies. In this case, the robotic capability is a general term and may define a whole production cell by its structure or may as well signify a single element of the production assembly such as a gripper. In the case of the E-maintenance ontology, serviced equipment is defined by properties such as function, components/subparts and maintenance.

Maintenance resources are the resources that are involved in the maintenance process. The resources may be physical resources (such as small piece of inventory, consumables, etc), human resources (such as internal personnel, external personnel), maintenance equipment, instruments and tools, knowledge materials (e.g. user manual, tables, electronic documents etc).

We developed the prototype E-maintenance ontology to support each phase of the overall maintenance process as seen in Fig. 3 it supports the five phases described in Fig. 1: Manage, Plan, Prepare, Execute and Assess.

The problem ontology is used to store and share the knowledge related to known problems and malfunctions that may be treated by an intervention or may be prevented by a maintenance procedure. The problem ontology accommodates a structured description of known problems that allows for the users (industrial robotic capabilities user) to add new problems as they arise during the operational life cycle. Individuals of the problem ontology may also develop explanations about the contingency plan drawn for known incidents. 
Intervention knowledge structures the knowledge related to the procedures that are to be undergone either as a preventive maintenance policy or as a corrective maintenance policy [5]. The intervention knowledge may accommodate standard solutions offered by the producers as well as alternative solutions introduced by integrators and amended both by producers and users.
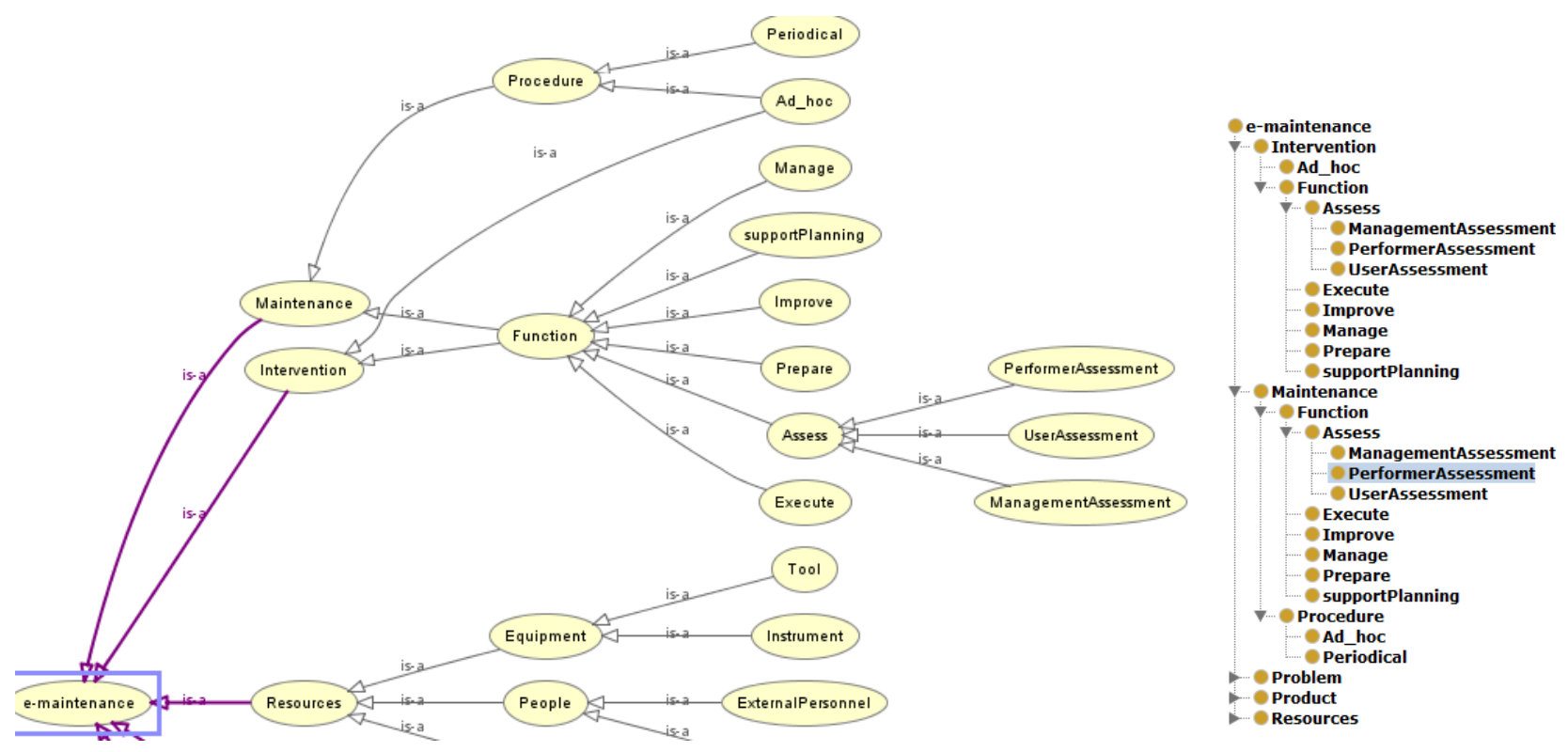

Fig. 3. Intervention and Maintenance ontology as seen in Protégé.

\section{Proof of concept.}

After defining the ontology structure, the next step was the validation of the concept. A case study regarding the maintenance of a robotic cell was taken into consideration. The goal of the experiment was to acquire and use maintenance knowledge for the robotic cell. The experiment involved several phases. One must note that in order to simplify both the acquisition of maintenance information and the interpretation of the results, the robotic cell was seen as being comprise of an industrial robot, a pneumatic gripper, a compressed air source and a power source (Fig. 4).

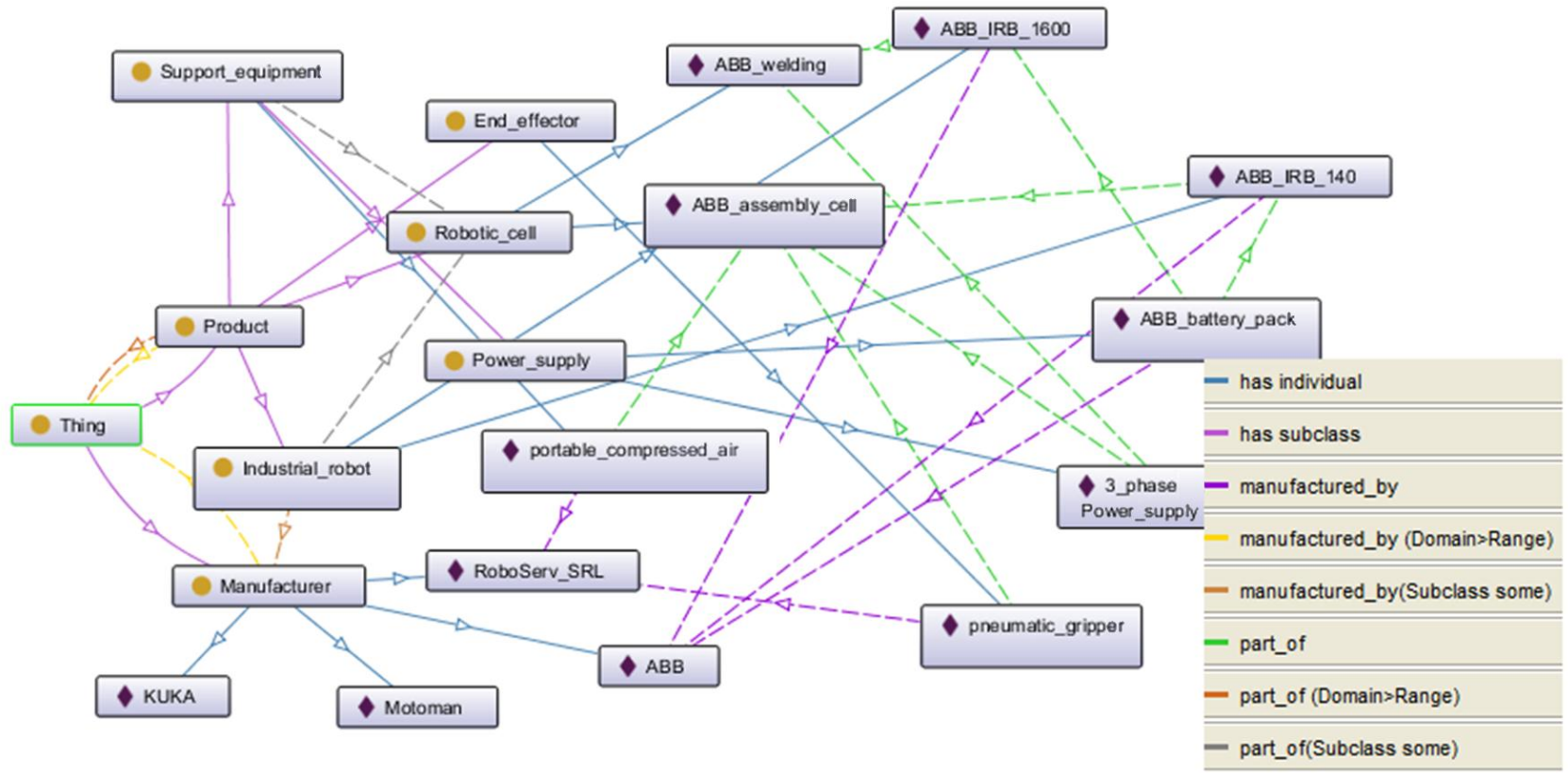

Fig. 4. Products in the E-Maintenance ontology.

Nodes, individuals and relations between the - a simplified view. 
Phase 1. Insertion of several individuals in the ontology, defining components of the robotic cell (e.g. pneumatic griper, power supply, different type of robots, etc.) based on maintenance knowledge gathered from the producers. In a real case the maintenance knowledge for each product is to be generated based on maintenance information from the producer of each product.

Phase 2. The definition of the production cell as a product in the e-maintenance ontology. This is done by a different stakeholder, namely the integrator of the robotic cell. The integrator is able to define the production facility as a structure composed of already predefined components (products). As stated before as an oversimplification our robotic cell will be comprised of a gripper, a power supply, a battery pack, a gripper and an air compressor.

Phase 3. For the third phase we had two scenarios, either an incident is signalled by an operator or by a monitoring system (one) or a new programmed maintenance that is to be undergone for a certain subcomponent of the robotic cell (two) is close.

Phase 4. The fourth phase implies the amendment of the maintenance procedures by the users and by the maintenance personnel. This is equivalent to the Assessment phase as shown in Fig. 1.

In order to better showcase the use of the ontology a prototype web application was created that infers maintenance information from the E-maintenance ontology starting from requests based on attributes such as product and incident.

The users are able to define new maintenance procedures or may use maintenance procedures shared by other stakeholders. The systems automatically amends the ad hoc (fix it) maintenance procedures based on the user feedback and on the most successful maintenance procedure.

The maintenance module allows the users to share knowledge related to a product maintenance based on the classification ontology scheme presented in Fig. 5. Thus, a user may access anytime the knowledge regarding the problems of the products (problems, causes, effects, solution) and the maintenance strategy.

\begin{tabular}{|c|c|c|c|c|c|c|}
\hline$\square$ ABB assembly cell & \multicolumn{3}{|l|}{ gripper } & \multicolumn{3}{|c|}{ search for mallfunction or maintenance } \\
\hline$\square$ structure & \multicolumn{6}{|c|}{ gripper malfunction } \\
\hline$\frac{\text { ABB IRB } 140}{\text { portable compressed ai... }}$ & \multicolumn{6}{|c|}{ gripper periodical service } \\
\hline battery pack & \multicolumn{6}{|c|}{ Problem/Solution } \\
\hline pneumatic gripper & Problem & Cause & Effect & \multicolumn{3}{|c|}{ Solution } \\
\hline$\boxminus \underline{\text { scheduled maintenance }}$ & \multirow{4}{*}{$\begin{array}{l}\text { gripper } \\
\text { malfunction }\end{array}$} & \multirow{3}{*}{$\begin{array}{l}\text { detached } \\
\text { air intake } \\
\text { compressed } \\
\text { air unit } \\
\text { malfunction }\end{array}$} & \multirow{4}{*}{$\begin{array}{l}\text { inability } \\
\text { to grasp } \\
\text { objects }\end{array}$} & \multicolumn{3}{|c|}{ 1. Check compressed air intake plug. } \\
\hline . & & & & \multicolumn{3}{|c|}{ 2. Check compressed air duct. } \\
\hline & & & & \multicolumn{3}{|c|}{$\begin{array}{l}\text { 3. Start compressed air unit. } \\
\text { 4. Check compressed air unit. } \\
\text { 5. Check endeffector unit. }\end{array}$} \\
\hline & & \multicolumn{4}{|l|}{$\begin{array}{l}\text { endeffect } \\
\text { or defect }\end{array}$} & \\
\hline & \multicolumn{3}{|l|}{ Product } & \multicolumn{3}{|c|}{ Maintenance } \\
\hline & Component & \multicolumn{2}{|c|}{ pneumatic_gripper } & \multirow{3}{*}{\multicolumn{2}{|c|}{$\begin{array}{l}\text { Maint. strategy } \\
\text { Service } \\
\text { responsible }\end{array}$}} & Ad-Hoc Maintenance \\
\hline & Part of & $\underline{\mathrm{ABB}}$ as & sembly cell & & & Personnel (int) \\
\hline & \multirow{2}{*}{ Function } & \multirow{2}{*}{\multicolumn{2}{|c|}{ Grasp objects }} & & & Maint. eng. (int) \\
\hline & & \multirow{2}{*}{\multicolumn{3}{|c|}{$\begin{array}{l}\text { Powerd by an external } \\
\text { compressed air unit. } \\
\text { portable compressed air unit }\end{array}$}} & & RoboServ SRL (ext) \\
\hline & Observation & & & & & \\
\hline & Producer & Gripper & rod SA & & & \\
\hline
\end{tabular}

Fig. 5. Web-based interface for the E-maintenance problem based quering.

In this case a predefined component is a component that has entries in the knowledge ontology for problems and maintenance strategy. When defining a production facility (e.g. robotic cell with gripper) the user is able to define his own maintenance policy by adding new procedures to the ones created by subcomponent producers. 
Information about the entire production system, as defined by the integrator, is displayed on the left with the help of a navigation tree graph. The user of the application may decide to browse the maintenance procedures for each procedure or to query the knowledge base for information regarding the appropriate maintenance procedures that are to be considered for a certain incident. The search string may be either a component name (e.g. related to gripper) or any word related to the malfunction.

The use of the maintenance knowledge that is structured within the E-maintenance ontology may be seen in the web based prototype application. The interface depicted in Fig. 5 offers information related to the product and to a product problem:

○ Product description (structure, type, name, function, manufacturer) compiled from the product knowledge related to the product;

- Maintenance (maintenance strategy, procedures, service responsible) inferred from the Maintenance Knowledge, Intervention knowledge and Resources Knowledge;

- Problem/Solution (problem, cause, effect, solution) from the Problem Knowledge and Intervention knowledge.

The print screen in Fig. 6 offers information related to a scheduled maintenance procedure. As seen in Fig 5, the web based application shows the next scheduled maintenance and points (via a link) to the appropriate maintenance procedure. In the example bellow one had chosen to obtain information about the scheduled maintenance for the battery pack. The application retrieved relevant knowledge related to the scheduled maintenance for the "battery_pack" product as defined by the producer.
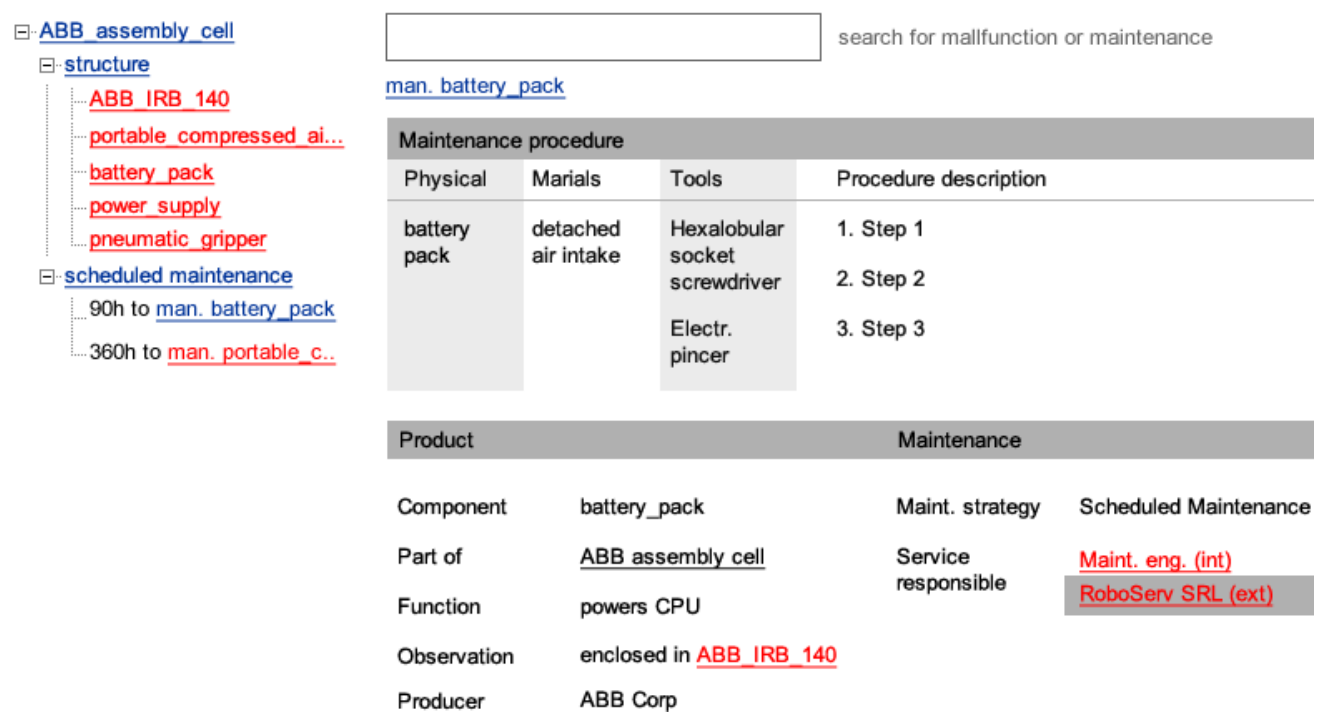

Fig. 6. Web-based interface for the E-maintenance Scheduled Maintenance procedure for battery pack.

\section{Further researches}

Research towards the development and extension of the proposed E-maintenance prototype and ontology, comprising a wider integration of the PSS's life-cycle, as well as addressing other economic sectors such as mining, transportation will be further taken into consideration. The integration of the E-maintenance prototype application with an online monitoring platform for distributed production capabilities is foreseen.

\section{Conclusions}

The paper presents a novel approach in the field of industrial robots maintenance, namely the use of ontologies within a software platform that will enable industrial robots stakeholders to share and use maintenance knowledge. The research here presented is part of a project aimed at creating an 
integrated e-monitoring and e-maintenance system. The solution supports the creation of a new business model for entities involved in the production, use, integration and maintenance of industrial robots capabilities. The current prototype will offer valuable insight into what a new business model based on shared knowledge principles may look like.

Our approach demonstrates the potential of integrating novel information system approaches such as ontologies for maintenance knowledge management, collaborative platform for new business model, in order to create a novel manufacturing facility management paradigm.

\section{Acknowledgments}

ACKNOWLEDGMENT: This paper was supported by the project "Development and support of multidisciplinary postdoctoral programmes in major technical areas of national strategy of Research - Development - Innovation" 4D-POSTDOC, contract no. POSDRU/89/1.5/S/52603, project cofunded by the European Social Fund through Sectoral Operational Programme Human Resources Development 2007-2013.

\section{References}

[1] Yang, X., Moore, P., Pu, J-S. and Wong, C-B., 2009, A Practical Methodology for Realizing Product Service Systems for Consumer Products, Computers \& Industrial Engineering, 56: 224-235.

[2] Eti, M.C., Ogaji, S.O.T. and Probert, S.D., 2006, "Reducing the cost of preventive maintenance (PM) through adopting a proactive reliability-focused culture", Applied Energy, Vol. 83, pp. 1235-48.

[3] T. Gruber. Toward principles for the design of ontologies used for knowledge sharing. International Journal of Human-Computer Studies, 43(5-6):907-928, 1995.

[4] Dhouib, S., Du Lac, N., Farges, J. L., Gerard, S., Hemaissia-Jeannin, M., Lahera-Perez, J., Millet, S., Patin, B., Stinckwich, S. Control architecture concepts and properties of an ontology devoted to exchanges in mobile robotics. In: 6th National Conference on Control Architectures of Robots, 2011.

[5] Markeset T, Kumar U., 2003, Design and development of product support and maintenance concepts for industrial systems. In: Journal of Quality in Maintenance Engineering 2003;9 (4), pages 376-92.

[6] Chioreanu, A., Brad, S., Ioanes, C., 2012, Vision on Intelligent Management of Industrial Robotics Systems, TransTech Publication, In: Applied Mechanics and Materials, vol. 162, pages: $368-377$.

[7] Candell, O., Karim, R., Soderholm, P., 2009, eMaintenance-Information logistics for maintenance support, In: Robotics and Computer-Integrated Manufacturing 25 (2009), pages: 937-944.

[8] Chungoora, N., Cutting-Decelle, A.-F., Young, R.I.M., Gunendran, A.G., Usman, Z., Harding, J.A. and Case, K., 2011. Towards the ontology-based consolidation of production-centric standards. In: 2011 International Journal of Production Research.

[9] Durán, O., 2011, Computer-aided maintenance management systems selection based on a fuzzy AHP approach, Advances in Engineering Software archive Volume 42 Issue 10, October, pages 821-829.

[10] Yoshikawa, H., 1995, Manufacturing and the 21st century - intelligent manufacturing systems and the renaissance of the manufacturing industry, In: Technological Forecasting and Social Change 49 (2), pages: 195-213.

[11] Elsevier Editorial, 2006, Special issue on e-maintenance, Computers in Industry 572006 , pages $473-475$. 